\section{Check for updates}

Cite this: Chem. Sci., 2019, 10, 9028

๑ All publication charges for this article have been paid for by the Royal Society of Chemistry

\title{
Far-red/near-infrared emitting, two-photon absorbing, and bio-stable amino-Si-pyronin dyes $\uparrow$
}

\author{
Kyeong Hwan Kim, ${ }^{a}$ Subhankar Singha, (D) *a Yong Woong Jun, (ID ${ }^{a}$ Ye Jin Reo, (D) ${ }^{a}$ \\ Hye Rim Kim, ${ }^{a}$ Hye Gun Ryu, ${ }^{a}$ Snehasis Bhunia ${ }^{b}$ and Kyo Han Ahn (D) *a
}

\begin{abstract}
Organic fluorophores emitting in the far-red/near-infrared (NIR) wavelength region are in great demand for minimal autofluorescence and reduced light scattering in deep tissue or whole body imaging. Currently, only a few classes of far-red/NIR fluorophores are available including widely used cyanine dyes, which are susceptible to photobleaching and form nonfluorescent aggregates. Even rare are those far-red/NIR emitting dyes that have two-photon imaging capability. Here we report a new class of far-red/NIRemitting dyes that are photo-stable, very bright, biocompatible, and also two-photon absorbing. The introduction of an electron-withdrawing group such as $\mathrm{N}$-acyl or $\mathrm{N}$-alkoxycarbonyl groups on the $\mathrm{C}-10$ amino substituent of the new julolidine-derived amino-Si-pyronin dyes (ASiPj), which emit in the far-red region, causes large bathochromic shifts, leading to NIR-emitting amino-Si-pyronin dyes (NIR-ASiP') having high cellular stability. Furthermore, the $A S^{j} P^{j}-N I R-A S i P^{j}$ couple offers a novel ratiometric bioimaging platform with a large spectral gap, as demonstrated here with a boronate-containing NIR$A \mathrm{AiP}^{\mathrm{j}}$ derivative that is converted to the corresponding $\mathrm{ASi} \mathrm{P}^{\mathrm{j}}$ dye upon reaction with hydrogen peroxide.
\end{abstract}

Received 10th May 2019

Accepted 3rd August 2019

DOI: $10.1039 / c 9 s c 02287 b$

rsc.li/chemical-science dyes with two-photon imaging capability, which are in great demand for long-term monitoring of biological analytes with minimal autofluorescence. ${ }^{8,9}$

Recently, Nagano and co-workers developed a family of farred/NIR fluorescent rhodamine analogues including Sirhodamine dyes $(\mathrm{SiR}){ }^{\mathbf{1 0}}$ since the first report on the Si-pyronin (SiP) core by Xiao, Qian and co-workers. ${ }^{11}$ Silicon analogues still possess the optical properties of the original rhodamine dyes, such as high fluorescence quantum yields, photostability and cell permeability. Accordingly, SiR dyes have recently received significant attention for the development of fluorescent probes ${ }^{\mathbf{1 2}}$ and fluorescence imaging techniques including super-resolution imaging and multicolor imaging. ${ }^{13-16}$ These conventional SiR dyes, which mostly emit in the far-red region, however, show very small Stokes shifts $(\Delta \lambda=\sim 18 \mathrm{~nm}),{ }^{\mathbf{1 4}}$ similar to BODIPY $(\Delta \lambda=\sim 10 \mathrm{~nm})^{17}$ and rhodamine dyes $(\Delta \lambda=\sim 20$ $\mathrm{nm}),{ }^{18}$ which raises the light reabsorption issue in bioimaging. Also, they have been rarely used for two-photon microscopy imaging, ${ }^{19}$ a powerful means for obtaining high-resolution 3D images of living specimens (including animal tissues) down to the depth of a millimeter along with reduced photo-damage and photo-bleaching. ${ }^{20,21}$

The fact that the conversion of BODIPY and rhodamine to the corresponding amino-BODIPY ${ }^{22}$ and amino-pyronin ${ }^{23,24}$ dyes shows large Stokes shifts ( $\sim 60$ and $\sim 105 \mathrm{~nm}$, respectively) and good two-photon absorbing properties ${ }^{25,26}$ prompted us to investigate the corresponding amino-Si-pyronin (ASiP) dyes and their derivatives. Earlier, a structurally simple 10-amino-Sixanthene precursor was used to synthesize $N$-acylated- 
iminoanthrone derivatives by Klán and co-workers. ${ }^{27}$ In the course of our study, ${ }^{28}$ Butkevich et al. reported alkylamino-Sipyronin dyes and their application to super-resolution fluorescence microscopy. ${ }^{29}$ Also, Guo and co-workers subsequently reported ASiP dyes with two-photon imaging application. ${ }^{30}$ We noticed that even though it was possible to induce large Stokes shifts and two-photon imaging capability by converting the "conventional" SiR dye system into the corresponding ASiP system, unfortunately, the reported ASiP analogues showed hypsochromic shifts in their emission and absorption spectra $(\Delta \lambda=\sim 50 \mathrm{~nm}$ in a buffer solution) from the corresponding SiR dyes. Accordingly, the ASiP dyes known so far showed the maximum emission wavelength $\left(\lambda_{\mathrm{em}}\right)$ of around $\sim 610 \mathrm{~nm}$, which belongs to the orange emission region, which would cause significant autofluorescence. ${ }^{8,9}$ To address this critical issue, it is necessary to develop fluorophores that emit in the far-red/NIR region. Currently, only a few classes of such dyes are available, which are mostly based on cyanines, ${ }^{31}$ BODIPYs, ${ }^{32}$ hemicyanine hybrids of rhodamines, fluoresceins and coumarins, ${ }^{33}$ silicon-based rhodamines, ${ }^{34}$ and benzocoumarins. ${ }^{8}$ To this end, we undertook a rational approach to develop a novel class of two-photon active, NIR-emitting ASiP derivatives (NIRASiP). At the same time, we also intended to modulate the photophysical properties of new ASiP dyes by implementing an "activable" functional group by an analyte or a stimulus, which would ultimately provide a ratiometric bioimaging platform (Fig. 1a). Although rhodamine and Si-rhodamine dyes have been widely used for the development of fluorescent probes, they mostly operate in the turn-on sensing mode through the lactam ring-opening process. For reliable and quantitative analysis, a ratiometric probe that shows signals at two different wavelengths with a large spectral separation is highly promising, as it avoids environmental and instrumental effects on fluorescence change. ${ }^{35}$ Herein, we disclose NIR-emitting ASiP dyes and their parent ASiP dyes, the couple of which also constitutes a promising ratiometric bioimaging platform with large spectral shifts.

\section{Results and discussion}

\section{Design and development of amino-Si-pyronin based two- photon absorbing NIR emitting dyes}

We reasoned that introducing an amine donor at C-10 of SiP dyes may impart electronic perturbation and intramolecular charge transfer (ICT) characteristics to the resulting dyes, which may endow them with two-photon absorbing properties as in the case of the amino-BODIPY system. ${ }^{25,26}$ In a further approach, modulating the electron-donating ability of the 10-amino group may induce bathochromic spectral shifts. Both approaches indeed ultimately have led to two-photon active, NIR-emitting Si-pyronin analogues.

Thus, starting from a bis(dimethylamino)-Si-xanthone intermediate (for its synthesis, see the ESI $\dagger$ ), we synthesized various amino-Si-pyronin compounds $\left(\mathrm{ASiP}^{\mathrm{a}} \mathbf{1 - 1 0}\right.$; Tables 1 and $\mathrm{S} 1, \mathrm{ESI} \dagger$ ) by introducing different types of alkylamines at C-10 of the Si-pyronin core. Then, the electron-donating ability of the

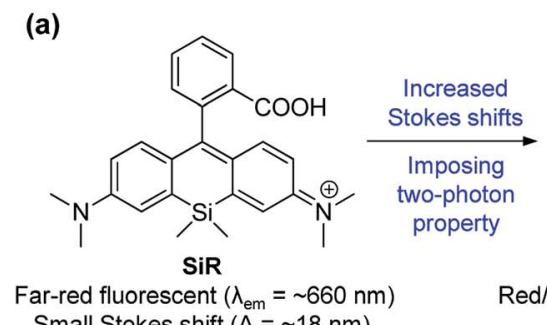

Far-red fluorescent $\left(\lambda_{\text {em }}=\sim 660 \mathrm{~nm}\right)$
Small Stokes shift $(\Delta=\sim 18 \mathrm{~nm})$

(b)

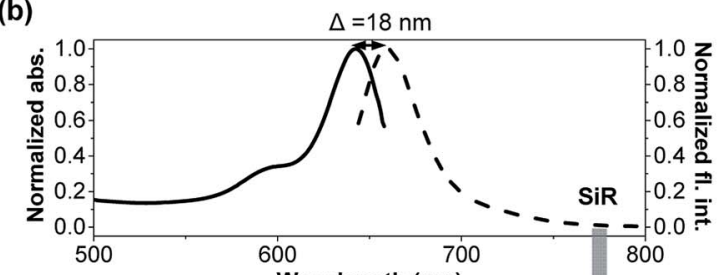

(c)

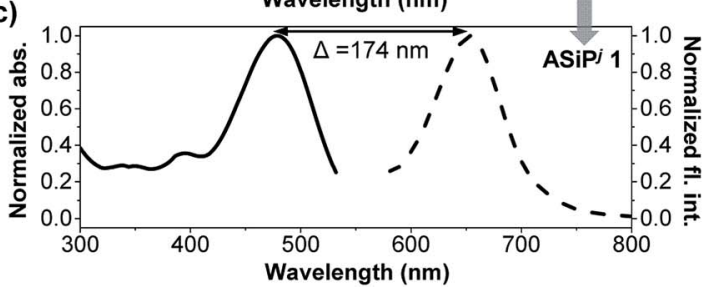

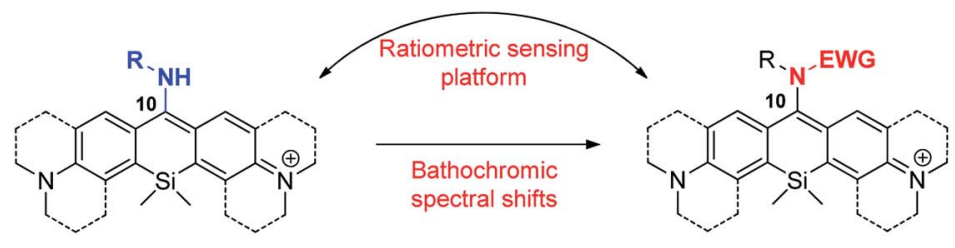

ASiP (R = alkyl)

Red/far-red fluorescent $\left(\lambda_{\text {em }}=\sim 610 / \sim 650 \mathrm{~nm}\right)$

Large Stokes shift $(\Delta=\sim 175 \mathrm{~nm})$

(d)

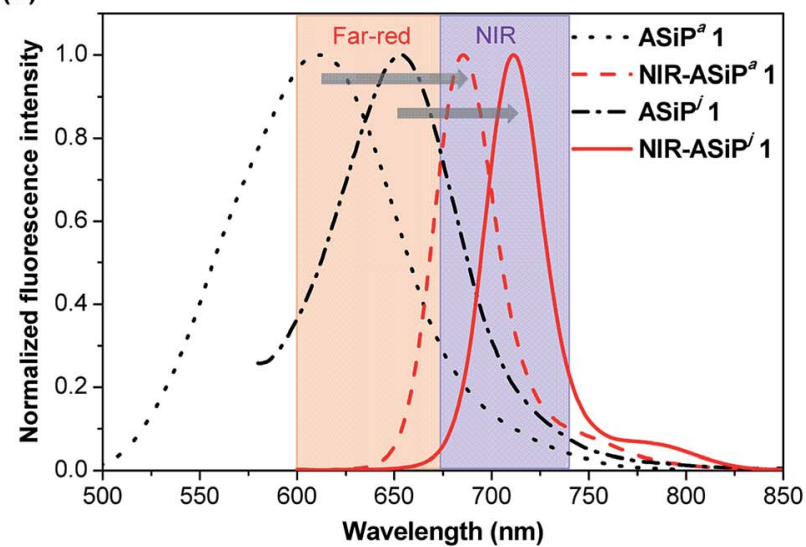

Fig. 1 (a) The design strategy used for NIR-emitting amino-Si-pyronin (NIR-ASiP) dyes as well as a ratiometric sensing platform. EWG = electron-withdrawing group. (b and c) Normalized absorption (solid line) and emission (dash line) spectra of SiR (b) and ASiP' 1 (c) in PBS ( $p H$ H 7.4) containing 1\% DMSO. (d) Emission spectral shift of ASiP dyes to NIR-ASiP dyes in PBS (pH 7.4) containing 1\% DMSO. The emission spectra were obtained by excitation at the maximum absorbance wavelength of each dye. 
Table 1 Photophysical properties of $\mathrm{ASiP}^{\mathrm{a}}$ and NIR-ASiP ${ }^{\mathrm{a}}$ analogues

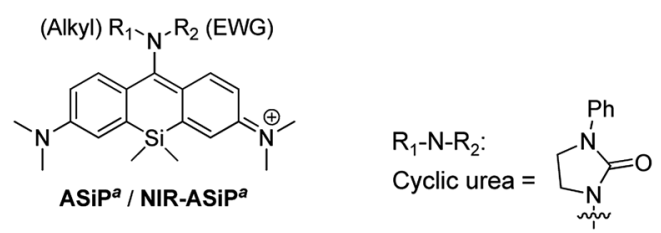

\begin{tabular}{llllll}
\hline & $R_{1}$ (alkyl) & $R_{2}(\mathrm{EWG})$ & $\lambda_{\text {abs }}{ }^{a} / \mathrm{nm}$ & $\lambda_{\mathrm{em}}{ }^{b} / \mathrm{nm}$ & $\Phi_{\mathrm{F}}{ }^{c}$ \\
\hline $\mathrm{ASiP}^{\mathrm{a}} \mathbf{1}$ & $\mathrm{Me}$ & $\mathrm{H}$ & 452 & 612 & $0.33^{d}$ \\
$\mathrm{ASiP}^{\mathrm{a}} \mathbf{2}$ & $\mathrm{Bn}$ & $\mathrm{H}$ & 469 & 623 & $0.34^{e}$ \\
$\mathrm{ASiP}^{\mathrm{a}}$ 3 & Propargyl & $\mathrm{H}$ & 473 & 628 & $0.25^{e}$ \\
NIR-ASiP $^{\mathrm{a}} \mathbf{1}$ & Me & $\mathrm{CO}_{2} \mathrm{Bn}$ & 669 & 685 & $0.42^{f}$ \\
NIR-ASiP $^{\mathrm{a}}$ 2 & Propargyl & $\mathrm{COCH}_{3}$ & 676 & 694 & $0.31^{e}$ \\
NIR-ASiP $^{\mathrm{a}}$ 3 & Propargyl & $\mathrm{COCF}_{3}$ & 684 & 707 & $0.27^{e}$ \\
NIR-ASiP $^{\mathrm{a}}$ 4 & Propargyl & $\mathrm{SO}_{2} \mathrm{CF}_{3}$ & 694 & 713 & $0.25^{e}$ \\
NIR-ASiP $^{\mathrm{5}} \mathbf{5}$ & Bn & $\mathrm{COCF}_{3}$ & 684 & 704 & $0.29^{e}$ \\
NIR-ASiP $^{\mathrm{a}} \mathbf{6}$ & Cyclic urea & & 674 & 690 & $0.22^{e}$
\end{tabular}

${ }^{a}$ Maximum absorption wavelength. ${ }^{b}$ Maximum emission wavelength in PBS (pH 7.4). ${ }^{c}$ Fluorescence quantum yield. ${ }^{d}$ Determined in methanol using fluorescein as the reference $\left(\Phi_{\mathrm{F}}=0.95\right.$ in $0.1 \mathrm{M}$ $\mathrm{NaOH}) .{ }^{18} e$ Determined in ethanol using rhodamine $101\left(\Phi_{\mathrm{F}}=0.915\right.$ in EtOH) as the reference dye. ${ }^{f}$ Determined in $\mathrm{CH}_{3} \mathrm{CN}$ using Nile blue $\left(\Phi_{\mathrm{F}}=0.27\right.$ in ethanol $)$ as the reference dye.

10-amino group was further modulated by attaching an electron-withdrawing group (EWG) to it, which provided the NIR-emitting $\mathrm{ASiP}^{\mathrm{a}}$ analogues.

The photophysical properties of $\mathrm{ASiP}^{\mathrm{a}}$ 1-10 measured in PBS (containing 1\% DMSO) show the one-photon absorption maxima at around 450-475 $\mathrm{nm}$ while the corresponding emission maxima at around 600-625 nm (Tables 1 and S1, ESI $\dagger$ ). We found that the propargylamine derivative $\mathrm{ASiP}^{\mathrm{a}} 3$ showed a little red-shift in the absorption and emission bands compared to those of the methylamine and benzylamine analogues, $\operatorname{ASiP}^{\mathrm{a}} \mathbf{1}$ and 2, which suggested that a further bathochromic shift would be induced by introducing a more electron-withdrawing substituent at C-10. Accordingly, we synthesized a carbamate derivative (NIR-ASiP ${ }^{\mathrm{a}}$ 1) and measured its photophysical properties. Indeed, NIR-ASiP ${ }^{a} \mathbf{1}$, which is the benzyl carbamate derivative of $\mathrm{ASiP}^{\mathrm{a}} \mathbf{1}$, exhibited large bathochromic shifts in the absorption and emission bands $(\Delta \lambda=218 \mathrm{~nm}$ and $75 \mathrm{~nm}$, respectively) with the maximum intensity peaks at $669 \mathrm{~nm}$ and $685 \mathrm{~nm}$, respectively (Table 1 and Fig. S1, ESI $\dagger$ ).

Computational calculations (using Gaussian '09) performed for $\mathrm{ASiP}^{\mathrm{a}} \mathbf{1}$ and a simplified carbamate form NIR-ASiP ${ }^{\mathrm{a}} \mathbf{1}$ gave a HOMO-LUMO energy gap of $2.97 \mathrm{eV}$ and $2.41 \mathrm{eV}$, respectively (Fig. S2, ESI $\dagger$ ), supporting the bathochromic spectral shifts upon attaching an electron-withdrawing group to the $\mathrm{C}-10$ amine site. The spectral tuning of such $\mathrm{ASiP}^{\mathrm{a}}$ dyes is thus readily realized by a simple transformation, avoiding laborious and complex synthetic operations.

\section{Bio-stability issues of NIR emitting NIR-ASiP ${ }^{a}$ dyes}

After characterizing the photophysical properties of the $\mathrm{ASiP}^{\mathrm{a}}$ dyes, we evaluated their cellular imaging capability toward
HeLa cells under one-photon $\left(\lambda_{\mathrm{ex}}=488 \mathrm{~nm}\right)$ and two-photon excitation $\left(\lambda_{\mathrm{ex}}=900 \mathrm{~nm}\right)$ conditions. The selected dyes $\mathrm{ASiP}^{\mathrm{a}}$ 2 and $\mathrm{ASiP}^{\mathrm{a}} 3$ provided very bright images by confocal laserscanning microscopy (CLSM) (Fig. S3a and b, ESI $\dagger$ ) as well as two-photon microscopy (TPM) (Fig. S3c and d, ESI $\dagger$ ). The excellent imaging capability of the $\mathrm{ASiP}^{\mathrm{a}}$ dyes under two-photon excitation further confirms their two-photon absorbing properties, as also reported by Guo and co-workers. ${ }^{30}$

Surprisingly, NIR-ASiP ${ }^{\text {a }} 1$ showed very dim cellular images when the emission was collected in the far-red/NIR wavelength region of 650-800 $\mathrm{nm}$ upon excitation at $633 \mathrm{~nm}$. In contrast, strong emission was observed in the shorter wavelength region of 500-630 nm upon excitation at $488 \mathrm{~nm}$ (Fig. 2a, panels A and G). The unexpected cellular imaging results of NIR-ASiP ${ }^{\mathrm{a}} \mathbf{1}$ indicated that the NIR-ASiP ${ }^{\mathrm{a}}$ type dyes are chemically unstable inside cells.

Indeed, NIR-ASiP ${ }^{\mathrm{a}} \mathbf{5}$ upon treatment with cysteine (Cys) or glutathione (GSH) in 1:1 PBS-dioxane at $37{ }^{\circ} \mathrm{C}$ showed little fluorescence in the NIR region, whereas a new emission band at around $600 \mathrm{~nm}$ corresponding to $\mathrm{ASiP}^{\mathrm{a}}$ increased as time went (Fig. S4 $\dagger$ ). The new band was due to the ASiP ${ }^{\mathrm{a}}$-type Cys-adduct, as confirmed by HPLC-MS and NMR analyses. The formation of the Cys-adduct also suggests that NIR-ASiP ${ }^{\mathrm{a}}$ type dyes also react with cellular proteins similarly through thiol addition followed by intramolecular amine substitution (Fig. 2b). ${ }^{36}$

Although the carbamate NIR-ASiP ${ }^{\mathrm{a}} 1$ seems to be less reactive that the trifluoroacetyl analogue 5 towards biothiols (Cys and GSH) in the buffer solution (Fig. S5, ESI $\dagger$ ), fluorescence from the shorter wavelength window was still observed in the cellular imaging data. This is likely due to the bioconjugation reactions with cellular proteins, as supported by a gel-electrophoresis analysis of A549 cells incubated with NIR-ASiP ${ }^{\mathrm{a}} 1(10 \mu \mathrm{M})$ for

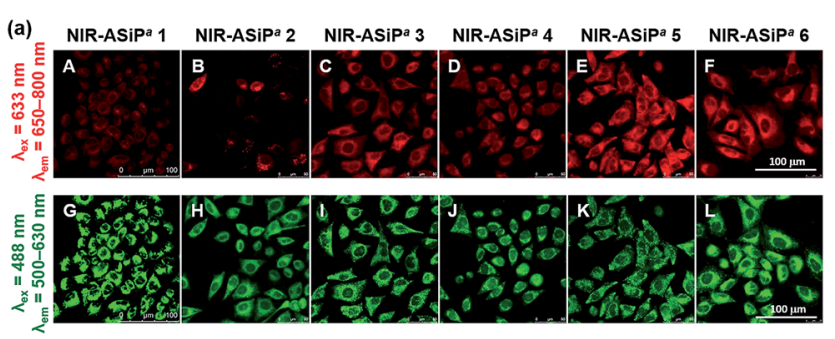

(b) Stability issue in cells

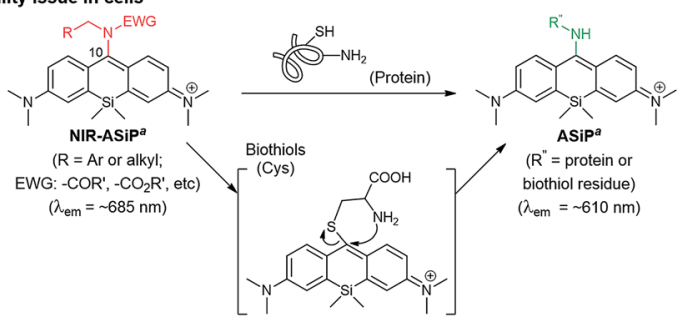

Fig. 2 (a) Images of A549 cells incubated with NIR-ASiP ${ }^{a}$ dyes $(10 \mu M)$ for $30 \mathrm{~min}$. Emission window/excitation wavelength: (A-F) 650-800 $\mathrm{nm} / 633 \mathrm{~nm}$; (G-L) 500-630 nm/488 nm. Scale bar: $100 \mu \mathrm{m}$. (b) NIR$\mathrm{ASiP}^{\mathrm{a}} 5$ reacts with Cys through thiol substitution followed by amine substitution to form the corresponding ASiP ${ }^{a}$-type product. Similarly, cellular proteins seem to react with NIR-ASiPa dyes, plausibly through thiol addition followed by intramolecular amine substitution. 
$1 \mathrm{~h}$ : a strong fluorescence band (broad) appeared, plausibly due to dye-labeled cellular proteins (Fig. S6, ESI†).

To secure the cellular stability of the NIR-ASiP ${ }^{\mathrm{a}}$ dyes, initially we varied the $\mathrm{C}-10$ amino group. Changing the amino group into the corresponding carboxamide, sulfonamide, cyclic urea, and other functional groups, in all cases, was found to be ineffective in securing the desirable cellular stability (see Table 1 for the dye structures and Fig. 2a for the corresponding cellular images).

Thus, a different approach was necessary to address the cellular instability issue of such NIR-ASiP ${ }^{\mathrm{a}}$ dyes.

\section{Securing bio-stability through developing julolidine-derived NIR-emitting amino-Si-pyronin dyes}

It is known that the $\mathrm{C}-10$ of $\mathrm{SiR}$ is more susceptible to nucleophilic attack compared to that of rhodamine dyes. Indeed, the high electrophilicity at the C-10 of SiR was used for the development of a GSH probe ${ }^{37,38}$ and for super-resolution imaging. ${ }^{39-44}$ Importantly, the electrophilicity at the C-10 of SiR is also dependent on the polarity of the medium: for example, a $2^{\prime}$-carboxy-SiR compound exists mainly in the nonfluorescent spirolactone form in less polar media due to the nucleophilic attack of the nearby carboxylate to the C-10, whereas it exists in the fluorescent zwitterionic form in highly polar media (Fig. 3b). ${ }^{39-42}$ Similarly, polarity-dependent electrophilicity at C-10 would be also expected for NIR-ASiP ${ }^{\mathrm{a}}$ in the cellular matrix, the less polar media compared to the aqueous buffer solution, plausibly causing the nucleophilic attack by biomolecules (biothiols or amines).

For electronic modulation at C-10, we also compared $\mathrm{ASiP}^{\mathrm{a}}$ derivatives with other amine substituents such as methoxyamine, phenylhydrazine or benzhydrazide (see Fig. S7 in the $\mathrm{ESI} \dagger$ for the dye structures). Unfortunately, all these $\mathrm{ASiP}^{\mathrm{a}}$ analogues showed a tendency to exist in the non-fluorescent form. Introducing a sterically bulky amine such as benzhydrylamine provided a bright $\mathrm{ASiP}^{\mathrm{a}}$ analogue, but subsequent attempts to attach any electron-withdrawing substituent to the amine site were found to be difficult.

Toward cellular-stable NIR-ASiP dyes, finally we turned our attention to the dye's core structure. Eventually, we were able to overcome the bio-instability of the NIR-ASiP ${ }^{\mathrm{a}}$ dyes by changing the dye skeleton, from bis(dimethylamino)-SiP ( $\mathrm{ASiP}^{\mathrm{a}}$ where a represents the acyclic amine donor) to julolidine-derived SiP (ASiP ${ }^{\mathrm{j}}$ ), as shown in Fig. 3a. In the resultant $\mathrm{ASiP}^{\mathrm{j}}$ dyes, the four alkyl substituents on the Si-xanthene core are expected to increase the electron density at C-10, in addition to increasing the steric hindrance around it. Gratifyingly, these effects together are found to stabilize the corresponding NIR-emitting dyes (NIR-ASiP') from possible nucleophilic attack by biothiols and amines inside cells.

Computational calculations using the Gaussian' 09 program (B3LYP/6-31+G(d)) for $\mathrm{ASiP}^{\mathrm{a}} \mathbf{1}$ and $\mathrm{ASiP}^{\mathrm{j}} \mathbf{1}$ showed that the Mulliken charge on the $\mathrm{C}-10$ of $\mathrm{ASiP}^{\mathrm{a}} 1$ is +0.193 a.u., whereas that of ASiP 1 is -0.143 a.u. Thus, the electrophilicity at C-10 is significantly lowered in $\operatorname{ASiP}^{\mathrm{j}} \mathbf{1}$ compared to that in $\mathrm{ASiP}^{\mathrm{a}} \mathbf{1}$. (a)

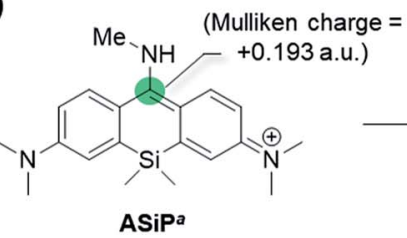

(b)

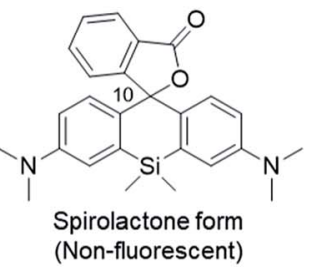

(c)

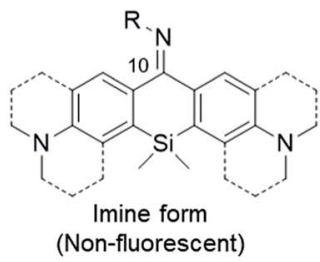

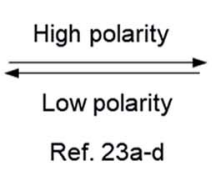
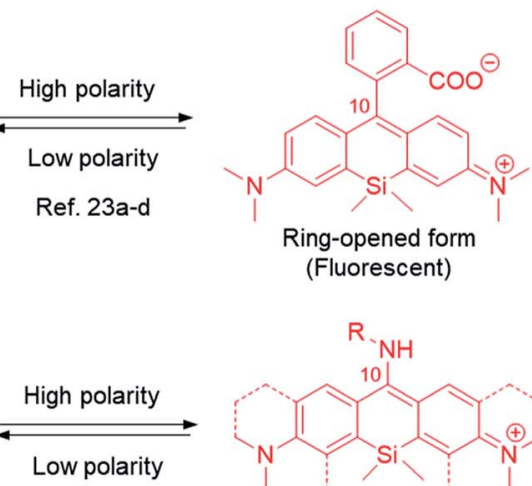

Low polarity

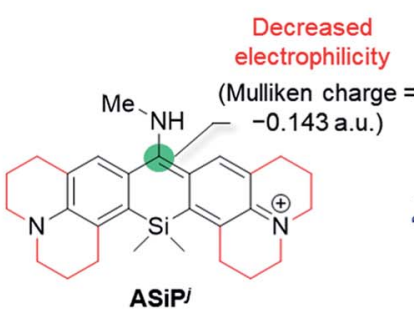

"Bathochromic shift"

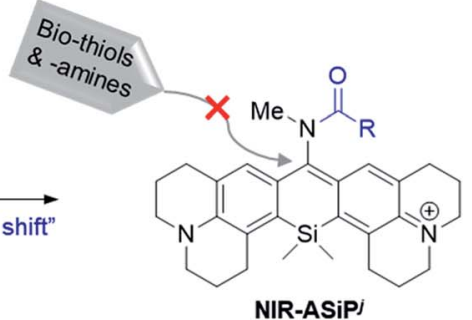

(d)

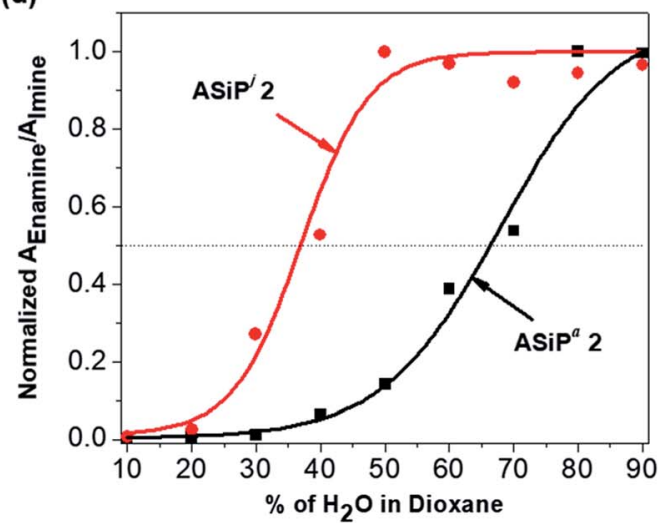

Fig. 3 (a) Far-red emitting julolidine-derived amino-Si-pyronin dyes (ASiPj) and their NIR-emitting derivatives (NIR-ASiPJ) that are stable inside cells. The corresponding Mulliken charges at C-10 of ASiP ${ }^{\mathrm{a}}$ and $\mathrm{ASiP} \mathrm{P}^{\mathrm{j}}$ are shown in atomic unit (a.u.). Structural changes of (b) SiR and (c) ASiP dyes depending on the polarity of the medium. (d) Changes of the normalized absorbance ratio of the enamine form (fluorescent) to the imine form (non-fluorescent) depending on the medium polarity (increasing water content in 1,4-dioxane), compared for ASiP 2 and ASipj 2. 
Moreover, the corresponding HOMO-LUMO energy gaps obtained for $\mathrm{ASiP}^{\mathrm{a}} 1$ and $\mathrm{ASiP}^{\mathrm{j}} 1$ were $-2.97 \mathrm{eV}$ and $-2.83 \mathrm{eV}$, respectively; hence, bathochromic spectral shifts are also expected upon introducing the alkyl substituents. ${ }^{11}$

The ASiP dyes' emission behavior is dependent on the medium polarity. ${ }^{29}$ By following the protocol established for carboxyphenyl-substituted Si-rhodamine dyes by Lukinavičius et $a .^{39,41}$ and Butkevich et al., ${ }^{\mathbf{4 0 , 4 2}}$ we compared the equilibrium behavior of two selected dyes, $\operatorname{ASiP}^{\mathrm{a}} 2$ and $\operatorname{ASiP}^{\mathrm{j}} 2$, depending on the medium polarity. The ASiP dyes can exist in two forms, the highly conjugated enamine and less conjugated imine forms, of which equilibrium that involves protonation/deprotonation is dependent on the media (Fig. 3c). ${ }^{29}$ The enamine form with an extended $\pi$-conjugation feature is strongly emissive, whereas the imine form is poorly emissive plausibly due to imine bond isomerization and short $\pi$-conjugation. A series of absorption spectra were recorded for the two selected dyes in water-dioxane media by varying the water content and hence the polarity (Fig. S8 and S9, ESI $\dagger$ ). The ratio of the enamine to the imine form for each of the ASiP dyes, as represented by the ratio of the corresponding absorbance, is plotted against the medium polarity (Fig. 3d). The data show that half of the $\operatorname{ASiP}^{\mathrm{a}} 2$ molecules exists in the fluorescent enamine form only in a medium of above $70 \%$ water-dioxane, whereas $\mathrm{ASiP}^{\mathrm{j}} 2$ is expected to remain in the fluorescent form over a wide range of polarity ( $>37 \%$ water-dioxane). Thus, we can conclude that the $\mathrm{ASiP}^{\mathrm{j}}$ skeleton is more electron-rich (that is, the enamine proton is less acidic) than the $\mathrm{ASiP}^{\mathrm{a}}$ skeleton. As a result, the $\mathrm{ASiP}^{\mathrm{j}}$ dyes are expected to show emission behavior even at cytosolic $\mathrm{pH}$ values. In contrast, the $\mathrm{ASiP}^{\mathrm{a}}$ dyes fluoresce only in acidic organelles such as lysosomes, but not in the cytosol (at neutral $\mathrm{pH}){ }^{30}$

\section{Photophysical properties of julolidine derived ASiP ${ }^{\mathrm{j}}$ and NIR- ASip $^{\mathrm{j}}$}

Encouraged by the theoretical calculation and the mediumdependent equilibrium data of $\mathrm{ASiP}^{\mathrm{j}}$, we synthesized several $\mathrm{ASiP}^{\mathrm{j}}$ compounds, by introducing methylamine (ASiP ${ }^{\mathrm{j}} \mathbf{1}$ ), benzylamine $\left(\mathrm{ASiP}^{\mathrm{j}} 2\right)$ and propargylamine $\left(\mathrm{ASiP}^{\mathrm{j}} 3\right)$ at $\mathrm{C}-10$ of the common julolidine-derived Si-xanthone intermediate (Table 2; for the detailed synthetic procedure, see the ESI $\dagger$ ).

Photophysical properties of the new $\mathrm{ASiP}^{\mathrm{j}}$ dyes were measured in different solvents (PBS, ethanol, acetonitrile, and

Table 2 Photophysical properties of ASiP ${ }^{j}$ and NIR-ASiPj derivatives

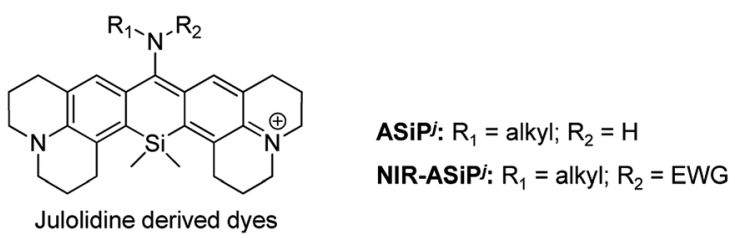

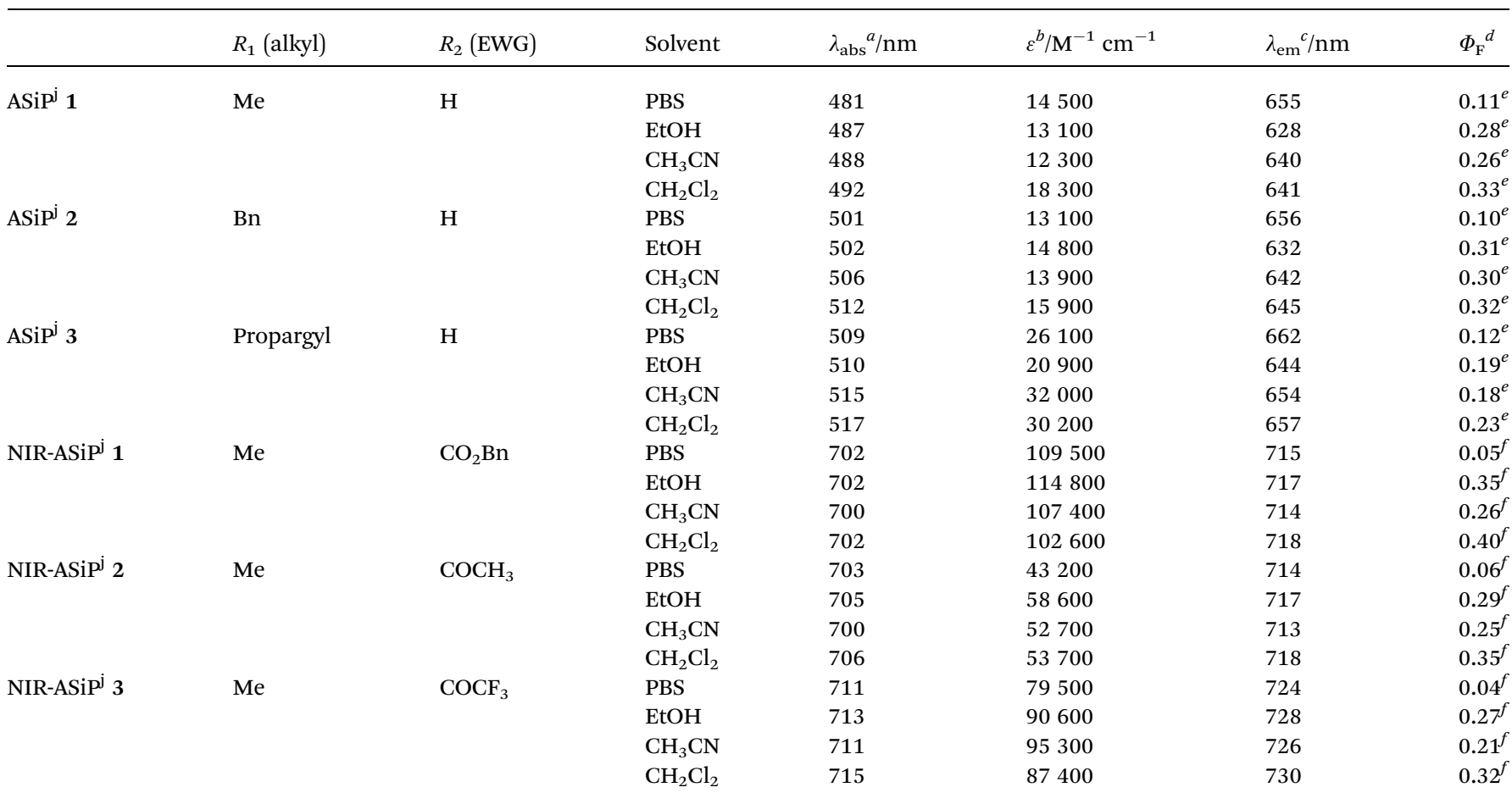

${ }^{a}$ Maximum absorption wavelength. ${ }^{b}$ Molar extinction coefficient. ${ }^{c}$ Maximum emission wavelength. ${ }^{d}$ Fluorescence quantum yields determined in $\mathrm{CH}_{3} \mathrm{CN}$ using ${ }^{e}$ fluorescein $(\Phi=0.95$ in $0.1 \mathrm{M} \mathrm{NaOH})$ or ${ }^{f}$ Nile blue $(\Phi=0.27$ in ethanol) as reference dyes. 
dichloromethane) (Table 2 and Fig. S10-S12, ESI†). In PBS, the absorption and emission maxima $\left(\lambda_{\mathrm{abs}}\right.$ and $\left.\lambda_{\mathrm{em}}\right)$ of the $\mathrm{ASiP}^{\mathrm{j}}$ dyes are in the range of 481-509 $\mathrm{nm}$ and $655-662 \mathrm{~nm}$, respectively. It is notable that, in comparison with the corresponding $\mathrm{ASiP}^{\mathrm{a}}$ analogues $\left(\lambda_{\mathrm{abs}} \sim 450 \mathrm{~nm} ; \lambda_{\mathrm{em}} \sim 610 \mathrm{~nm}\right)$ that emit in the yellow to orange wavelength region, $\mathrm{ASiP}^{\mathrm{j}}$ dyes emit in the farred region $\left(\lambda_{\mathrm{em}} \sim 650-660 \mathrm{~nm}\right)$, similar to the SiR dyes $\left(\lambda_{\mathrm{em}} \sim\right.$ $660 \mathrm{~nm}$ ). This bathochromic shift to the far-red emission is crucial to avoid the significant autofluorescence from biomolecules in the yellow emission channel in tissue imaging under two-photon excitation conditions. ${ }^{8,9}$ An added value of the $\mathrm{ASiP}^{\mathrm{j}}$ dyes is the large Stokes shift $(\Delta \lambda=\sim 175 \mathrm{~nm})$, a contrasting feature from conventional SiR dyes $(\Delta \lambda=\sim 18 \mathrm{~nm})$ (Fig. $1 \mathrm{~b}$ and c).

Moreover, the $\mathrm{ASiP}^{\mathrm{j}}$ dyes also show bright one-photon emission $\left(\Phi_{\mathrm{F}}=0.11-0.33\right)$ and good two-photon absorbing properties (TPACS value, $\delta=113-122 \mathrm{GM}$ ) under excitation at $800 \mathrm{~nm}$. Furthermore, the ASiP ${ }^{\mathrm{j}}$ dyes show strong fluorescence at acidic as well as neutral $\mathrm{pH}(\mathrm{pH} 3-7)$; at basic $\mathrm{pH}$ (above $\mathrm{pH}$ 8), the fluorescence gradually diminishes due to the equilibrium shift to the non-fluorescent imine form (Fig. S13, ESI†).

Similarly to the case of $\mathrm{ASiP}^{\mathrm{a}}$, finally we synthesized several NIR emitting dyes based on ASiP ${ }^{j}$ : benzyl carbamate (NIR-ASiP ${ }^{j}$ 1), acetamide (NIR-ASiP ${ }^{j}$ ) and trifluoroacetamide (NIR-ASiP ${ }^{j}$ 3) derivatives as the representative dyes (Table 2; for the detailed synthetic procedure, see the ESI $\dagger$ ). Photophysical properties of the NIR-ASiP ${ }^{j}$ dyes were measured in different solvents (PBS, ethanol, acetonitrile, and dichloromethane).

All the NIR-ASip ${ }^{j}$ dyes show large bathochromic shifts in the absorption and emission bands, emitting in the NIR region above $700 \mathrm{~nm}$ (Fig. 1c, Table 2 and Fig. S14-S16, ESI $\dagger$ ). For example, NIR-ASiP ${ }^{j} 1$ in PBS shows further bathochromic shifts of $\sim 30 \mathrm{~nm}$ in the absorption and emission bands $\left(\lambda_{\mathrm{abs}}=\right.$ $702 \mathrm{~nm} ; \lambda_{\mathrm{em}}=715 \mathrm{~nm}$ ) compared to the corresponding acyclic analogue NIR-ASiP ${ }^{\mathrm{a}} 1\left(\lambda_{\mathrm{abs}}=669 \mathrm{~nm} ; \lambda_{\mathrm{em}}=685 \mathrm{~nm}\right)$. Thus, NIRASiP $^{\mathrm{j}} 1$ in PBS shows giant bathochromic shifts of $\sim 250 \mathrm{~nm}$ in the absorbance band and $\sim 105 \mathrm{~nm}$ in the emission band from those of the corresponding $\mathrm{ASiP}^{\mathrm{a}} \mathbf{1}$. Also, all the NIR-ASiP ${ }^{\mathrm{j}}$ dyes show good quantum yields $(\Phi=0.05-0.40)$ (Table 2$)$ and $\mathrm{pH}^{-}$ insensitive NIR emission covering a wide range of $\mathrm{pH}(\mathrm{pH}=$ 2-10) (Fig. S17, ESI $\dagger$ ). The latter property is notable in comparison with the $\mathrm{pH}$-dependent fluorescence emission behavior of the $\mathrm{ASiP}^{\mathrm{a}}$ dyes. An interesting observation is that compared to the $\operatorname{ASiP}^{\mathrm{j}}$ dyes $(\Delta \lambda=153-174 \mathrm{~nm}$ in PBS), the corresponding NIR-ASiP ${ }^{j}$ dyes have much smaller Stokes shifts $\left(\Delta \lambda=11-13 \mathrm{~nm}\right.$ in PBS). Similarly, the ASiP ${ }^{\mathrm{a}}$ dyes have large Stokes shifts $(\Delta \lambda=154-160 \mathrm{~nm}$ in PBS) but the corresponding NIR-ASiP ${ }^{\mathrm{a}}$ dyes have much smaller Stokes shifts $(\Delta \lambda=16-23 \mathrm{~nm}$ in PBS).

In comparison with the well-known NIR emitting cyanine dye (Cy 7: IR780) that undergoes fast photo-oxidation, all the new NIR-ASiP $\mathrm{P}^{\mathrm{j}}$ dyes show excellent photostability under continuous irradiation at $633 \mathrm{~nm}\left(22 \mu \mathrm{W} \mathrm{cm} \mathrm{cm}^{-2}\right)$, usual CLSM imaging conditions or at $900 \mathrm{~nm}\left(145 \mathrm{~mW} \mathrm{~cm}^{-2}\right)$, and harsh two-photon imaging conditions, both in PBS at $\mathrm{pH} 7.4$ for 10 min (Fig. S19, ESI†).

\section{Bioimaging capabilities of $\mathrm{ASi}^{\mathrm{j}}$ and NIR-ASip}

Above all, it was our keen concern whether the new NIR-ASiP ${ }^{\mathrm{j}}$ dyes would have cellular stability or not. We assessed their cellular imaging behavior along with their parent $\mathrm{ASiP}^{\mathrm{j}}$ dyes under one-photon excitation at $488 \mathrm{~nm}$ as well as two-photon excitation at $900 \mathrm{~nm}$. Both the $\mathrm{ASiP}^{\mathrm{j}}$ and NIR-ASiP ${ }^{\mathrm{j}}$ dyes showed little cell toxicity from standard CCK assays (Fig. S20 and S21†). A549 cells incubated with each of the ASiP ${ }^{\mathrm{j}}$ dyes 1-3 at $1.0 \mu \mathrm{M}$ show very bright images using CLSM and TPM (Fig. 4a and c). The bio-stability of the NIR-ASiP ${ }^{j}$ dyes $1-3$ was evaluated using CLSM, by collecting the emissions from two separate channels: (1) a far-red/NIR window (650-800 nm) under

(a)
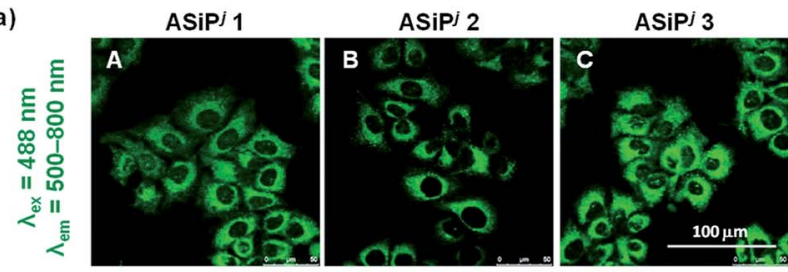

(b)
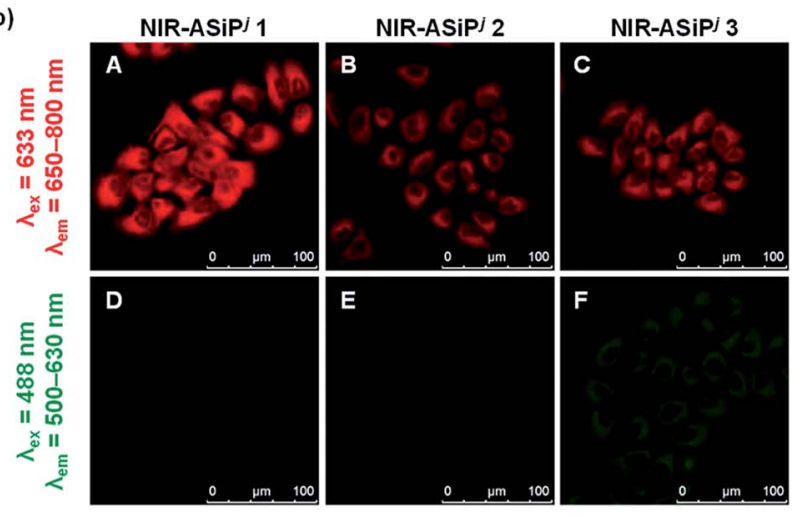

(c)
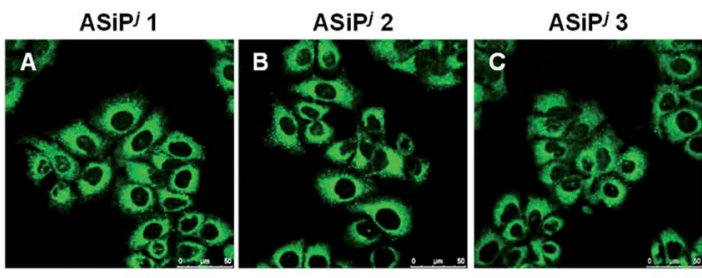

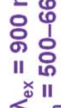
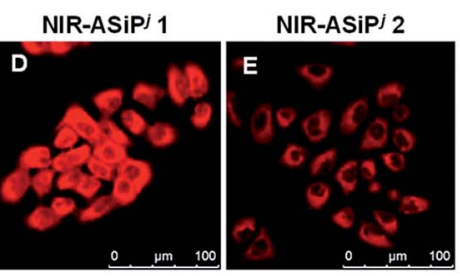

NIR-ASiPj 3

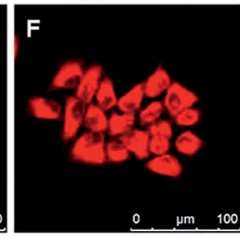

Fig. 4 (a) CLSM images of A549 cells incubated with ASiPj dyes (1.0 $\mu \mathrm{M})$ for $30 \mathrm{~min}$. The images were obtained by excitation at $488 \mathrm{~nm}$ and collection of the emissions in the range of 500-800 nm. (b) CLSM images of A549 cells incubated with NIR-ASiPj dyes $(10 \mu \mathrm{M})$ for $30 \mathrm{~min}$. The images were obtained by collecting emissions either from $(A-C)$ the NIR channel $(650-800 \mathrm{~nm})$ under excitation at $633 \mathrm{~nm}$ or from $(D-F)$ the green channel $(500-630 \mathrm{~nm})$ under excitation at $488 \mathrm{~nm}$. (c) TPM images of $A \mathrm{SiP}^{\mathrm{j}}(\mathrm{A}-\mathrm{C})$ and NIR-ASiPj$(\mathrm{D}-\mathrm{F})$ dyes. The images were obtained by excitation at $900 \mathrm{~nm}$ and collection of the emissions in the range of 500-665 $\mathrm{nm}$. Scale bar: $100 \mu \mathrm{m}$. 
excitation at $633 \mathrm{~nm}$, to collect emissions from NIR-ASiP $\mathrm{P}^{\mathrm{j}}$ and (2) a shorter wavelength emission window (500-630 nm) under excitation at $488 \mathrm{~nm}$, to collect emissions of any possible decomposed dyes from NIR-ASiPj. To our delight, unlike previous NIR-ASiP ${ }^{\mathrm{a}} \mathbf{1}$, the NIR-ASiP ${ }^{\mathrm{j}}$ dyes 1 and 2 show bright cellular images in the NIR emission window (650-800 nm) (in Fig. 4b, panels A and B) but negligible images in the shorter emission window (in Fig. 4b, panels D and E). Only in the case of the trifluoroacetamide derivative, NIR-ASiP ${ }^{\mathrm{j}} 3$, a slight interference was observed in the short emission window (in Fig. 4b, panel F).

In solution, the julolidine-based NIR-ASiP ${ }^{j}$ dyes also showed chemical stability toward Cys and GSH, in contrast to the corresponding NIR-ASiP ${ }^{\mathrm{a}}$ dyes (Fig. S4 $\dagger$ ). The results confirm that we have addressed the stability issue by modifying the dye skeleton.

Thus, we can conclude that such NIR-ASiP ${ }^{\mathrm{j}}$ dyes have biostability sufficient for cellular imaging applications. Furthermore, the new NIR-ASiP ${ }^{j}$ dyes provide very bright TPM images under excitation at $900 \mathrm{~nm}$ (in Fig. 4c, panels D-F), a commonly accessible wavelength with commercial TPM, which also confirms their strong two-photon absorbing properties.

We also studied the intracellular distribution of the representative NIR-ASiP $\mathbf{1}$ by co-localization experiments using commercial reference dyes for the nucleus (Hoechst), lysosomes (LysoTracker green) and mitochondria (MitoTracker green), respectively. The results show that NIR-ASiP ${ }^{\mathrm{j}} \mathbf{1}$ does not localize in the nucleus (Pearson's correlation coefficient, $\mathrm{PCC}=-0.30$ ) and lysosomes $(\mathrm{PCC}=0.54)$ but mostly localizes in the mitochondria ( $\mathrm{PCC}=0.73$ ), possibly due to the hydrophobic and cationic character (Fig. S22, ESI $\dagger$ ).

In short, we have developed Si-pyronin based NIR-emitting dyes (NIR-ASip ${ }^{\mathrm{j}}$ dyes) with secured cellular stability. Together with the parent amino-Si-pyronin (ASiP ${ }^{j}$ ) dyes, the new NIR emitting dyes are photostable, biocompatible, and also provide very bright cellular images under both one- and two-photon excitation conditions. These dyes emit in the far-red or higher wavelength regions, which is crucial for imaging of tissues with minimal autofluorescence interference by TPM.

\section{Launching a unique ratiometric imaging platform through developing a ratiometric probe for $\mathrm{H}_{2} \mathrm{O}_{2}$}

One of our aims in this study was to develop a ratiometric sensing platform based on the ASiP ${ }^{\mathrm{j}}-\mathrm{NIR}-\mathrm{ASiP} \mathrm{P}^{\mathrm{j}}$ couple. The dye couple would constitute a promising ratiometric sensing system if the latter could be converted into the former triggered by an analyte or other stimuli, which will be accompanied by a considerable spectral shift $(\Delta \lambda>60 \mathrm{~nm})$. To demonstrate this scenario, we have prepared a fluorescent probe $\mathbf{A S i}^{\mathbf{j}}-\mathbf{H}_{2} \mathbf{O}_{2}$ (Fig. 5a) having a boronate group, which is well known to react with hydrogen peroxide. ${ }^{45}$

Hydrogen peroxide $\left(\mathrm{H}_{2} \mathrm{O}_{2}\right)$, the major reactive oxygen species, is vital to a certain level for normal cell functions such as cell signaling and defense. ${ }^{46}$ On the other hand, abnormal generation or accumulation of $\mathrm{H}_{2} \mathrm{O}_{2}$ can cause several human diseases including cancer and Alzheimer's and Parkinson's

(a)

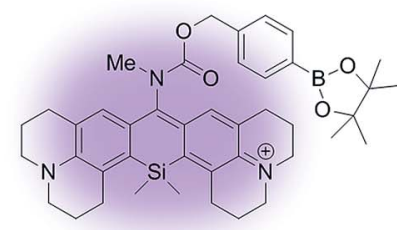

$\mathrm{H}_{2} \mathrm{O}_{2}$ Probe $\left(\mathrm{ASiP}^{\mathrm{j}} \mathrm{H}_{2} \mathrm{O}_{2}\right)$ NIR fluorescent

(b)

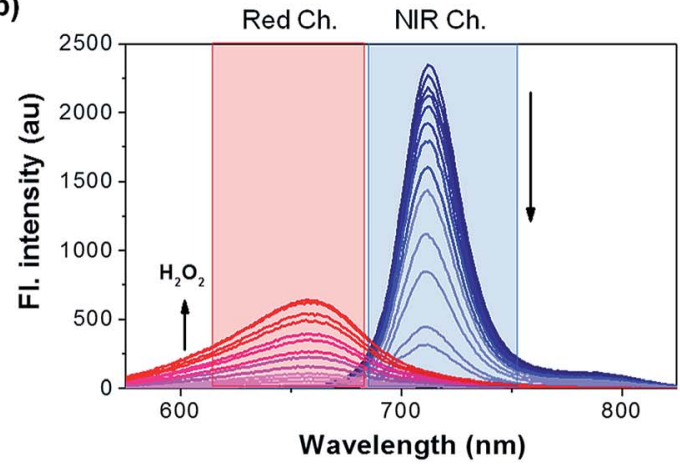

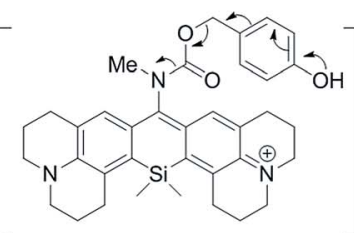

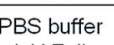

$(\mathrm{pH} 7.4)$

(1)

.

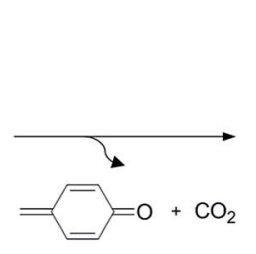

$+\mathrm{CO}_{2}$

(c)

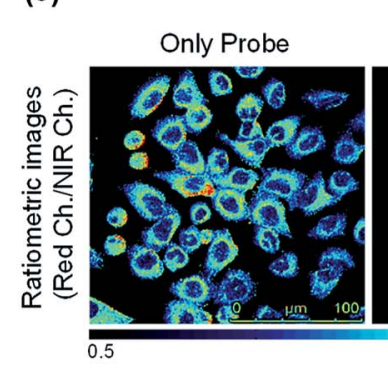

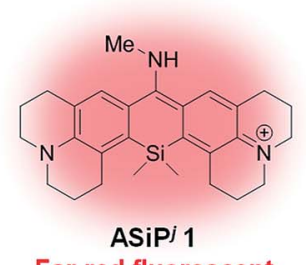

Far-red fluorescent

Fig. 5 (a) A ratiometric sensing scheme. (b) Time dependent fluorescence changes of the probe $(10 \mu M)$ in the presence of $\mathrm{H}_{2} \mathrm{O}_{2}(200 \mu M)$ in PBS (10 mM, pH 7.4), showing a gradual decrease of the NIR emission at $712 \mathrm{~nm}$ (excitation at $702 \mathrm{~nm}$ ) with the concomitant increase of the far-red emission at $655 \mathrm{~nm}$ (excitation at $481 \mathrm{~nm}$ ). (c) Ratiometric imaging $\left(I_{\text {Red }} / I_{\mathrm{NIR}}\right)$ of $\mathrm{H}_{2} \mathrm{O}_{2}$ in $\mathrm{A} 549$ cells using the probe: the cells were incubated with either the probe alone ( $10 \mu \mathrm{M}$; incubation for $30 \mathrm{~min}$ ) or with the probe and exogenously added $\mathrm{H}_{2} \mathrm{O}_{2}$ ( 50 and $200 \mu \mathrm{M}$; incubation for 30 min). The ratio images $\left(/_{\text {Red }} / I_{\text {NIR }}\right)$ were constructed from the pixel-to-pixel intensity ratio of the images collected in the red channel $(500-650 \mathrm{~nm}, \lambda$ ex $=$ $488 \mathrm{~nm})$ to those collected in the NIR channel $\left(650-800 \mathrm{~nm}, \lambda_{\text {ex }}=633 \mathrm{~nm}\right)$. Scale bar: $100 \mu \mathrm{m}$. 
diseases. ${ }^{47,48}$ Therefore, efficient detection methods of $\mathrm{H}_{2} \mathrm{O}_{2}$ levels in biological systems are in high demand. In the presence of $\mathrm{H}_{2} \mathrm{O}_{2}$, the boronate moiety of the NIR emitting probe (ASipi ${ }_{\text {- }}$ $\mathbf{H}_{2} \mathbf{O}_{2}$ ) would undergo oxidative cleavage to generate a selfimmolative carbamate intermediate, which in turn would undergo spontaneous decarboxylation to generate far-red fluorescent $\mathrm{ASiP}^{\mathrm{j}} 1$ as the product (Fig. 5a). As we expected, the probe emitted in the NIR region with the maximum peak at $712 \mathrm{~nm}$ when excited at $702 \mathrm{~nm}$ (the wavelength of maximum absorbance) (Fig. 5b). Upon the addition of $\mathrm{H}_{2} \mathrm{O}_{2}$ to a solution of the probe $(10 \mu \mathrm{M}$ in $10 \mathrm{mM}$ PBS, $\mathrm{pH} 7.4)$, the probe peak gradually decreased, while a new emission peak at $655 \mathrm{~nm}$ started to increase when excited at $481 \mathrm{~nm}$, the wavelength of maximum absorbance of $\mathrm{ASiP}^{\mathrm{j}} \mathbf{1}$. The corresponding absorption spectra also showed a gradual shift from the $\operatorname{NIR}\left(\lambda_{\text {abs }}=702\right.$ $\mathrm{nm})$ to visible region $\left(\lambda_{\mathrm{abs}}=481 \mathrm{~nm}\right)$ (Fig. S23, ESI $\dagger$ ). The fluorescence intensity ratio between the two peaks $\left(I_{655} / I_{712}\right)$ showed a linear increase with time as well as with the concentrations of $\mathrm{H}_{2} \mathrm{O}_{2}$ (Fig. S24-S27, ESI $\dagger$ ). The limit of detection was calculated to be as low as $9 \mathrm{nM}$ (Fig. S27†). Thus, the probe is highly sensitive and can be used to detect low concentrations of endogenous $\mathrm{H}_{2} \mathrm{O}_{2}$ in cells. The probe also showed excellent selectivity towards $\mathrm{H}_{2} \mathrm{O}_{2}$ over various competing species such as ATP, NAD, metal ions (Fe(III), Fe(II), Zn(II), and $\mathrm{Cu}$ (II)), biothiols (GSH and Cys), reactive nitrogen species (NO) and other reactive oxygen species ( ${ }^{t} \mathrm{BuOOH},{ }^{t} \mathrm{BuOO}^{\circ}, \mathrm{HO}^{\circ}$, and $\mathrm{HOCl}$ ) (Fig. S28, ESI $\dagger$ ). After confirming the excellent sensing properties of the probe in solution, we applied it for the ratiometric imaging of $\mathrm{H}_{2} \mathrm{O}_{2}$ in A549 cells. The cells were incubated with either the probe alone or with the probe and exogenously added $\mathrm{H}_{2} \mathrm{O}_{2}$ as a positive control. The images were captured in two separate emission channels: (1) an NIR channel (650-800 nm; $\lambda_{\text {ex }}=633$ $\mathrm{nm}$ ) for the probe and (2) a red channel (500-650 nm; $\lambda_{\mathrm{ex}}=488$ $\mathrm{nm})$ for the product. The ratio $\left(I_{\mathrm{Red}} / I_{\mathrm{NIR}}\right)$ images were constructed from the pixel-to-pixel intensity ratios of the images collected in the red channel to those collected in the NIR channel. The data show the lowest intensity ratio for the cells treated with the probe alone, but a gradual increase in the intensity ratio as the exogenous $\mathrm{H}_{2} \mathrm{O}_{2}$ concentration was increased (Fig. 5c).

The results demonstrate that the $\mathrm{ASiP}^{\mathrm{j}}-\mathrm{NIR}-\mathrm{ASiP} \mathrm{P}^{\mathrm{j}}$ couple provides a novel sensing platform that enables ratiometric cellular imaging of a biological analyte, here $\mathrm{H}_{2} \mathrm{O}_{2}$, with a minimal spectral overlap through the collection of emissions from NIR to far-red channels, which is promising in that we can minimize the significant autofluorescence from the green and yellow emission channels. By introducing various analytespecific reactive groups through a self-immolative linker at the 10-amino group of $\mathrm{ASiP}^{\mathrm{j}}$ dyes, similarly we could generate ratiometric imaging probes for other analytes of biological importance.

\section{Conclusions}

Organic dyes that absorb and emit in the biological optical window (650-950 $\mathrm{nm}$ ) are in great demand for bioimaging with reduced light scattering and minimal autofluorescence interference. Only a few classes of such fluorophores are currently available, demanding a new type of far-red/NIR emitting dye. Even rare are those far-red/NIR emitting dyes with twophoton imaging capability. We have developed a novel class of such fluorophores based on a new Si-pyronin dye platform. The introduction of $N$-acyl or $N$-alkoxycarbonyl groups on the amine nitrogen of known amino-Si-pyronin dyes causes large bathochromic shifts, leading to the new NIR fluorophores. The promising in vitro photophysical properties of the dyes, however, deteriorated in cells, owing to unexpected chemical conversions. This cellular instability issue was eventually solved by changing the known Si-xanthene core into a new julolidinederived one. The new julolidine-derived amino-Si-pyronin $\left(\mathrm{ASiP}^{\mathrm{j}}\right)$ and the corresponding NIR-emitting derivatives (NIR$\mathrm{ASiP}^{\mathrm{j}}$ ) emit in the far-red and NIR wavelength regions, respectively, afford very bright cellular images, and also have good two-photon absorbing properties. In addition, the new fluorophores are biocompatible, photostable, and have satisfactory water solubility. Furthermore, the NIR-ASiP ${ }^{j}$ dyes, coupled with the corresponding $\mathrm{ASiP}^{\mathrm{j}}$ dyes, offer a unique ratiometric imaging platform that enables bioimaging with minimal spectral overlap, as demonstrated with a ratiometric hydrogen peroxide probe. The new dye systems thus hold great promise for bioimaging application and for the development of ratiometric imaging probes.

\section{Experimental section}

The detailed experimental procedures for the measurement of one-photon and two-photon photophysical properties, cell viability assay, and synthesis and characterization data of the new dyes and probe (NMR and HR-mass spectra) are provided in the ESI. $\dagger$ Only the synthetic procedures of NIR-ASiP ${ }^{j}$ 1-3 are described here.

\section{Synthesis of NIR-ASiP ${ }^{j} 1$}

A solution of $\mathrm{ASiP}^{\mathrm{j}} \mathbf{1}(30 \mathrm{mg}, 0.05 \mathrm{mmol})$ in anhydrous dichloromethane $(5 \mathrm{~mL})$ at $0{ }^{\circ} \mathrm{C}$ was treated with diisopropylethylamine $(44 \mu \mathrm{L}, 0.25 \mathrm{mmol})$ and pyridine $(40 \mu \mathrm{L}, 0.5 \mathrm{mmol})$, and the mixture was stirred for $10 \mathrm{~min}$ at $0{ }^{\circ} \mathrm{C}$ followed by the addition of benzyl chloroformate $(71 \mu \mathrm{L}, 0.5 \mathrm{mmol})$. The reaction mixture, after being stirred at room temperature for $3 \mathrm{~h}$, was diluted with dichloromethane and washed with $1 \mathrm{~N} \mathrm{HCl}$. The organic layer was evaporated and the residue was subjected to flash column chromatography (eluent: $\mathrm{CH}_{2} \mathrm{Cl}_{2} / \mathrm{MeOH}=95 / 5$ ) to afford the product, which was further purified by preparative HPLC (XBD-C18; gradient 30/70-100/0 A : B over $40 \mathrm{~min}, \mathrm{~A}=$ acetonitrile, $\mathrm{B}=0.1 \%$ TFA in water, flow rate $=20 \mathrm{~mL} \mathrm{~min}^{-1}$ ) to obtain the pure product ( $4 \mathrm{mg}, 11 \%$ ) as a green solid. ${ }^{1} \mathrm{H}$ NMR (500 MHz, $\left.\mathrm{CD}_{3} \mathrm{OD}, 298 \mathrm{~K}, \delta\right): 7.25-7.21$ (m, 3H), 7.10-7.05 (m, $4 \mathrm{H}), 5.04(\mathrm{~s}, 2 \mathrm{H}), 3.61-3.57(\mathrm{~m}, 8 \mathrm{H}), 3.22(\mathrm{~s}, 3 \mathrm{H}), 2.96-2.94(\mathrm{~m}$, $4 \mathrm{H}), 2.72-2.68(\mathrm{~m}, 2 \mathrm{H}), 2.62-2.58(\mathrm{~m}, 2 \mathrm{H}), 2.06-2.05(\mathrm{~m}, 4 \mathrm{H})$, 1.97-1.96 (m, 4H), and $0.67(\mathrm{~d}, J=6.0 \mathrm{~Hz}, 6 \mathrm{H}) ;{ }^{13} \mathrm{C} \mathrm{NMR}(125$ $\left.\mathrm{MHz}, \mathrm{CD}_{3} \mathrm{OD}, 298 \mathrm{~K}, \delta\right): 161.0,160.5,157.2,157.1,152.0,142.9$, 142.7, 138.3, 137.9, 135.2, 133.4, 129.9, 129.7, 129.6, 129.5, 129.2, 128.9, 126.6, 125.9, 125.7, 69.2 , 68.8, 53.1, 52.5, 40.0, 39.8, 
33.2, 30.9, 30.6, 30.1, 28.9, 28.8, 26.2, 22.1, 21.9, 14.6, -0.7, and -0.8; HRMS (ESI) $m / z:[\mathrm{M}]^{+}$calcd for $\mathrm{C}_{36} \mathrm{H}_{42} \mathrm{~N}_{3} \mathrm{O}_{2} \mathrm{Si}^{+}, 576.3046$; found, 576.3042 .

\section{Synthesis of NIR-ASip 2}

A solution of $\mathrm{ASiP}^{\mathrm{j}} \mathbf{1}(30 \mathrm{mg}, 0.05 \mathrm{mmol})$ in anhydrous dichloromethane $(5 \mathrm{~mL})$ at $0{ }^{\circ} \mathrm{C}$ was treated with 2,6-lutidine ( 87 $\mu \mathrm{L}, 0.75 \mathrm{mmol}$ ) and stirred for $10 \mathrm{~min}$ at $0{ }^{\circ} \mathrm{C}$, followed by the addition of acetyl chloride $(36 \mu \mathrm{L}, 0.5 \mathrm{mmol})$. The resulting mixture, after being stirred at room temperature for $12 \mathrm{~h}$, was diluted with dichloromethane and washed with $1 \mathrm{~N} \mathrm{HCl}$. The organic layer was evaporated and the residue was subjected to column chromatography (eluent: $\mathrm{CH}_{2} \mathrm{Cl}_{2} / \mathrm{MeOH}=95 / 5$ ) to afford the product, which was further purified by preparative HPLC (XBD-C18; gradient 30/70-100/0 A : B over $40 \mathrm{~min}, \mathrm{~A}=$ acetonitrile, $\mathrm{B}=0.1 \%$ TFA in water, flow rate $=20 \mathrm{~mL} \mathrm{~min}^{-1}$ ) to obtain the pure product (5 mg, 15\%) as a green solid. ${ }^{1} \mathrm{H}$ NMR $\left(500 \mathrm{MHz}, \mathrm{CD}_{3} \mathrm{OD}, 298 \mathrm{~K}, \delta\right): 7.10(\mathrm{~s}, 2 \mathrm{H}), 3.63-3.60(\mathrm{~m}, 8 \mathrm{H}), 3.22$ (s, 3H), 2.98-2.95 (m, 4H), 2.79-2.77 (m, 4H), 2.09-2.06 (m, 4H), 2.03-2.00 (m, 4H), $1.83(\mathrm{~s}, 3 \mathrm{H})$, and $0.68(\mathrm{~s}, 6 \mathrm{H}) ;{ }^{13} \mathrm{C}$ NMR (125 $\left.\mathrm{MHz}, \mathrm{CD}_{3} \mathrm{OD}, 298 \mathrm{~K}, \delta\right): 173.0,160.2,152.2,142.6,134.7,134.0$, 127.2, 125.4, 53.2, 53.1, 52.6, 39.1, 30.1, 28.9, 22.0, 21.9, and -0.8; HRMS (ESI) $m / z$ : $[\mathrm{M}]^{+}$calcd for $\mathrm{C}_{30} \mathrm{H}_{38} \mathrm{~N}_{3} \mathrm{OSi}^{+}, 484.2784$; found, 484.2781 .

\section{Synthesis of NIR-ASip 3}

A solution of $\mathrm{ASip}^{\mathrm{j}} \mathbf{1}(30 \mathrm{mg}, 0.05 \mathrm{mmol})$ in anhydrous dichloromethane $(10 \mathrm{~mL})$ at $0{ }^{\circ} \mathrm{C}$ was treated with diisopropylethylamine $(44 \mu \mathrm{L}, 0.25 \mathrm{mmol})$ and stirred for $10 \mathrm{~min}$ at $0{ }^{\circ} \mathrm{C}$, followed by the addition of trifluoroacetic anhydride $(21 \mu \mathrm{L}$, $0.15 \mathrm{mmol}$ ). The resulting mixture, after being stirred at room temperature for $3 \mathrm{~h}$, was diluted with dichloromethane and washed with $1 \mathrm{~N} \mathrm{HCl}$. The organic layer was evaporated and the residue was subjected to column chromatography (eluent: $\left.\mathrm{CH}_{2} \mathrm{Cl}_{2} / \mathrm{MeOH}=95 / 5\right)$ to afford the product, which was further purified by preparative HPLC (XBD-C18; gradient 30/70-100/ $0 \mathrm{~A}$ : $\mathrm{B}$ over $40 \mathrm{~min}, \mathrm{~A}=$ acetonitrile, $\mathrm{B}=0.1 \% \mathrm{TFA}$ in water, flow rate $\left.=20 \mathrm{~mL} \mathrm{~min}^{-1}\right)$ to obtain the pure product $(7 \mathrm{mg}$, $21 \%)$ as a green solid. ${ }^{1} \mathrm{H}$ NMR $\left(500 \mathrm{MHz}, \mathrm{CD}_{3} \mathrm{OD}, 298 \mathrm{~K}, \delta\right): 7.08$ $(\mathrm{s}, 2 \mathrm{H}), 3.64-3.62(\mathrm{~m}, 8 \mathrm{H}), 3.40(\mathrm{~s}, 3 \mathrm{H}), 2.98-2.96(\mathrm{~m}, 4 \mathrm{H}), 2.80-$ $2.76(\mathrm{~m}, 4 \mathrm{H}), 2.09-2.06(\mathrm{~m}, 4 \mathrm{H}), 2.01-1.99(\mathrm{~m}, 4 \mathrm{H})$, and $0.69(\mathrm{~d}, J$ $=15.0 \mathrm{~Hz}, 6 \mathrm{H}) ;{ }^{13} \mathrm{C} \mathrm{NMR}\left(125 \mathrm{MHz}, \mathrm{CD}_{3} \mathrm{OD}, 298 \mathrm{~K}, \delta\right): 156.5$, $152.2,142.2$, 134.6, 134.2, 134.0, 133.9, 127.1, 127.1, 125.5, 123.6, 57.6, 53.3, 53.2, 52.6, 41.6, 30.9, 30.1, 28.9, 28.8, 22.0, 21.9, -0.7, and -1.0; HRMS (ESI) $m / z$ : $[\mathrm{M}]^{+}$calcd for $\mathrm{C}_{30} \mathrm{H}_{35^{-}}$ $\mathrm{F}_{3} \mathrm{~N}_{3} \mathrm{OSi}^{+}$, 538.2502; found, 538.2505.

\section{Conflicts of interest}

The authors are listed as co-inventors of a patent application related to the technology described in this work.

\section{Acknowledgements}

This work is financially supported by the Global Research Laboratory Program (2014K1A1A2064569) through the National
Research Foundation (NRF) funded by the Ministry of Science, ICT \& Future Planning, Republic of Korea. S. Singha acknowledges support from the Basic Science Research Program (2018R1D1A1B07051403) through the National Research Foundation (NRF) of Korea funded by the Ministry of Education.

\section{Notes and references}

1 C. K. Rosenthal, et al., Nat. Cell Biol., 2009, 11, 1165.

2 J. Zhang, R. E. Campbell, A. Y. Ting and R. Y. Tsien, Nat. Rev. Mol. Cell Biol., 2002, 3, 906.

3 R. Weissleder, Nat. Biotechnol., 2001, 19, 316.

4 J. V. Frangioni, Curr. Opin. Chem. Biol., 2003, 7, 626.

5 L. D. Lavis and R. T. Raines, ACS Chem. Biol., 2014, 9, 855.

6 J. B. Pawley, Handbook of confocal microscopy, Plenum Press, NY, USA, 2nd edn, 1995.

7 A. H. Herz, Photogr. Sci. Eng., 1974, 18, 323.

8 Y. W. Jun, H. R. Kim, Y. J. Reo, M. Dai and K. H. Ahn, Chem. Sci., 2017, 8, 7696.

9 D. Kim, H. Moon, S. H. Baik, S. Singha, Y. W. Jun, T. Wang, K. H. Kim, B. S. Park, J. Jung, I. Mook-Jung and K. H. Ahn, J. Am. Chem. Soc., 2015, 137, 6781.

10 Y. Koide, Y. Urano, K. Hanaoka, T. Terai and T. Nagano, ACS Chem. Biol., 2011, 6, 600.

11 M. Fu, Y. Xiao, X. Qian, D. Zhao and Y. Xu, Chem. Commun., 2008, 1780.

12 T. Ikeno, T. Nagano and K. Hanaoka, Chem.-Asian J., 2017, 12, 1435.

13 Y. Koide, Y. Urano, K. Hanaoka, W. Piao, M. Kusakabe, N. Saito, T. Terai, T. Okabe and T. Nagano, J. Am. Chem. Soc., 2012, 134, 5029.

14 T. Wang, Q.-J. Zhao, H.-G. Hu, S.-C. Yu, X. Liu, L. Liu and Q.-Y. Wu, Chem. Commun., 2012, 48, 8781.

15 T. Egawa, K. Hanaoka, Y. Koide, S. Ujita, N. Takahashi, Y. Ikegaya, N. Matsuki, T. Terai, T. Ueno, T. Komatsu and T. Nagano, J. Am. Chem. Soc., 2011, 133, 14157.

16 Y. Kushida, T. Nagano and K. Hanaoka, Analyst, 2015, 140, 685.

17 Y. Gabe, T. Ueno, Y. Urano, H. Kojima and T. Nagano, Anal. Biochem., 2006, 386, 621.

18 M. Beija, C. A. M. Afonso and J. M. G. Martinho, Chem. Soc. Rev., 2009, 38, 2410.

19 Z. Mao, H. Jiang, X. Song, W. Hu and Z. Liu, Anal. Chem., 2017, 89, 9620.

20 D. Kim, H. G. Ryu and K. H. Ahn, Org. Biomol. Chem., 2014, 12, 4550 .

21 H. M. Kim and B. R. Cho, Chem. Rev., 2015, 115, 5014.

22 J. Bañuelos, V. Martín, C. F. A. Gómez-Durán, I. J. A. Córdoba, E. Peña-Cabrera, I. García-Moreno, Á. Costela, M. E. Pérez-Ojeda, T. Arbeloa and Í. L. Arbeloa, Chem.-Eur. J., 2011, 17, 7261.

23 H. Zhang, J. Liu, Y.-Q. Sun, Y. Huo, Y. Li, W. Liu, X. Wu, N. Zhu, Y. Shi and W. Guo, Chem. Commun., 2015, 51, 2721. 24 X. Zhou, Y. Zeng, C. Liyan, X. Wu and J. Yoon, Angew. Chem., Int. Ed., 2016, 55, 4729. 
25 K. N. Bobba, M. Won, I. Shim, N. Velusamy, Z. Yang, J. Qu, J. S. Kim and S. Bhuniya, Chem. Commun., 2017, 53, 11213.

26 Y. W. Jun, T. Wang, S. Hwang, D. Kim, D. Ma, K. H. Kim, S. Kim, J. Jung and K. H. Ahn, Angew. Chem., Int. Ed., 2018, 57, 10142.

27 P. Horváth, P. Šebej, T. Šolomek and P. Klán, J. Org. Chem., 2015, 80, 1299.

28 K. H. Ahn, H. G. Ryu, Y. W. Jun, K. H. Kim and S. Singha, One- or two-photon absorbing fluorescent dyes based on amino-Si-pyronin compound and the uses thereof, KOR 102017-0110708, 2017.

29 A. N. Butkevich, G. Lukinavičius, E. D'Este and S. W. Hell, J. Am. Chem. Soc., 2017, 139, 12378.

30 H. Zhang, J. Liu, L. Wang, M. Sun, X. Yan, J. Wang, J.-P. Guo and W. Guo, Biomaterials, 2018, 158, 10.

31 W. Sun, S. Guo, C. Hu, J. Fan and X. Peng, Chem. Rev., 2016, 116, 7768.

32 H. Lu, J. Mack, Y. Yang and Z. Shen, Chem. Soc. Rev., 2014, 43, 4778.

33 H. Chen, B. Dong, Y. Tang and W. Lin, Acc. Chem. Res., 2017, 50, 1410.

34 T. Ikeno, T. Nagano and K. Hanaoka, Chem.-Asian J., 2017, 12, 1435.

35 M. H. Lee, J. S. Kim and J. L. Sessler, Chem. Soc. Rev., 2015, 44, 4185.

36 J. Tang, Z. Guo, Y. Zhang, B. Bai and W.-H. Zhu, Chem. Commun., 2017, 53, 10520.

37 K. Umezawa, M. Yoshida, M. Kamiya, T. Yamasoba and Y. Urano, Nat. Chem., 2017, 9, 279.
38 H. Nie, L. Qiao, W. Yang, B. Guo, F. Xin, J. Jing and X. Zhang, J. Mater. Chem. B, 2016, 4, 4826.

39 G. Lukinavičius, K. Umezawa, N. Olivier, A. Honigmann, G. Yang, T. Plass, V. Mueller, L. Reymond, I. R. Corrêa Jr, Z.-G. Luo, C. Schultz, E. A. Lemke, P. Heppenstall, C. Eggeling, S. Manley and K. Johnsson, Nat. Chem., 2013, 5, 132.

40 A. N. Butkevich, G. Y. Mitronova, S. C. Sidenstein, J. L. Klocke, D. Kamin, D. N. H. Meineke, E. D'Este, P.-T. Kraemer, J. G. Danzl, V. N. Belov and S. W. Hell, Angew. Chem., Int. Ed., 2016, 55, 3290.

41 G. Lukinavičius, L. Reymond, K. Umezawa, O. Sallin, E. D'Este, F. Göttfert, H. Ta, S. W. Hell, Y. Urano and K. Johnsson, J. Am. Chem. Soc., 2016, 138, 9365.

42 A. N. Butkevich, V. N. Belov, K. Kolmakov, V. V. Sokolov, H. Shojaei, S. C. Sidenstein, D. Kamin, J. Matthias, R. Vlijm, J. Engelhardt and S. W. Hell, Chem.-Eur. J., 2017, 23, 12114.

43 S.-N. Uno, M. Kamiya, T. Yoshihara, K. Sugawara, K. Okabe, M. C. Arhan, H. Fujita, T. Funatsu, Y. Okada, S. Tobita and Y. Urano, Nat. Chem., 2014, 6, 681.

44 E. Kozma, G. E. Girona, G. Paci, E. A. Lemke and P. Kele, Chem. Commun., 2017, 53, 6696.

45 D. Srikun, E. W. Miller, D. W. Domaille and C. J. Chang, J. Am. Chem. Soc., 2008, 130, 4596.

46 E. A. Veal, A. M. Day and B. A. Morgan, Mol. Cell, 2007, 26, 1. 47 T. Finkel, M. Serrano and M. A. Blasco, Nature, 2007, 448, 767.

48 K. J. Barnham, C. L. Masters and A. I. Bush, Nat. Rev. Drug Discovery, 2004, 3, 205. 